\title{
Liderança de mulheres em pastorais e comunidades católicas e suas retribuições*
}

Gabriele dos Anjos**

\begin{abstract}
Resumo
O texto trata da militância de mulheres de classes populares em clubes de mães, Comunidades Eclesiais de Base e Pastorais da Igreja Católica. A diferenciação entre "líderes" e demais participantes, e as motivações e os interesses específicos ao engajamento e à militância como "líder" são compreendidos a partir da análise das retribuições à atividade militante e suas relações com o exercício da liderança e com o conjunto de significados ligados à ação militante.
\end{abstract}

Palavras-chave: Militância Feminina, Classes Populares, Comunidades Católicas.

\footnotetext{
" Recebido para publicação em novembro de 2007, aceito em setembro de 2008.

** Doutora em Sociologia pela Universidade Federal do Rio Grande do Sul (UFRGS), Pesquisadora da Fundação de Economia e Estatística (FEE), Porto Alegre.gabrieleanjos@gmail.com
}

cadernos pagu (31), julho-dezembro de 2008:509-534. 
Liderança de mulheres em pastorais e comunidades católicas

Women's Leadership in Catholic Communities and Pastorals and their Retributions

\begin{abstract}
This paper covers the militancy of popular class women within Mothers' Clubs, Ecclesiastical Communities and Pastorals of the Catholic Church. Such militancy implies a differentiation between "leaders" and the other participants. This differentiation is defined by specific motivations and interests related to the commitment and militancy as "leader" in these forms of association. These motivations and interests can be understood by analyzing the rewards for militant activities and their relationships with the exercise of leadership and with the meanings associated with militant action.
\end{abstract}

Key Words: Women's Militancy, Popular Classes, Catholic Communities. 
Gabriele dos Anjos

\section{Introdução}

As Pastorais católicas e as Comunidades Eclesiais de Base

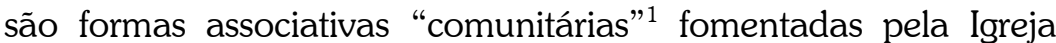
Católica que permitem a leigos, a maioria de classes sociais menos favorecidas, bem como a profissionais dessa Igreja, o chamado "trabalho comunitário" em nome de "problemas" ou causas com grande legitimidade, como a "defesa da vida" ou a "justiça social". Esse trabalho gratuito ou "voluntário" é fundado no desinteresse material e definido em relação à atividade econômica, que exige ação "estratégica" para a obtenção de ganhos materiais. ${ }^{2}$ Ao mesmo tempo, implica na adesão a valores como a "solidariedade", o "amor à humanidade" ou ao "próximo". O "trabalho voluntário" pode ser tomado como uma modalidade de ação militante, ao considerarmos militância a adesão a determinada "causa" e engajamento continuado em nome dela (Gaxie, 1977:130; 2005:161). Esse tipo de engajamento e militância desinteressados corresponde também às formas socialmente consagradas de atuação feminina no espaço público, como voluntariado em nome de problemas que dizem respeito ao altruísmo e à moral: a defesa da "vida", as crianças, a família. Ao mesmo tempo, remete a valores partilhados por "todos", o que

\footnotetext{
1 A "comunidade" em pauta, referenciada na Igreja Católica, comporta definições contextuais e, portanto, variadas. A tendência "progressista" da Igreja enfatiza a primazia da "comunidade de crentes" em relação ao clero. Há ainda a definição de "comunidade" como o conjunto dos membros de uma paróquia dedicada aos "serviços" nela realizados. Finalmente, a noção de "comunidade" também se refere à identidade de uma população definida pela proximidade física, pelo interconhecimento (Banck, 1990:74) e por problemas ou questões comuns relativas ao "local". No caso, a participação na comunidade dá origem ao engajamento em clubes de mães ou pastorais, e ao "trabalho" ou "militância" "comunitários" aqui tratados.

2 Uma definição de trabalho voluntário, como "atividades que as pessoas fazem de graça para ajudar instituições ou outras pessoas que não sejam parentes $e$ amigos", é enunciada na pesquisa de Landim e Scalon (2000:52) sobre trabalho voluntário e doação.
} 
Liderança de mulheres em pastorais e comunidades católicas

contribui para sua "naturalidade" enquanto fenômeno social e impede o questionamento de suas condições sociais de realização.

Por outro lado, os estudos que abordam a expressiva participação feminina nessas formas associativas católicas ${ }^{3}$ trabalham a partir de perspectivas que não questionam as condições que propiciam essa militância de mulheres de grupos populares (Burdick, 1990:153; Drogus, 1999:36-7; Alvarez, 1980:381; Machado e Mariz, 1997:74). Esses estudos enfatizam as possibilidades de ação política abertas a mulheres pobres a partir de seu engajamento em CEBs ou apontam os limites de superação da dominação masculina dados por esse tipo de militância (Machado e Mariz, 1997:76; Burdick, 1990:161), entendida como um paradoxo da ação coletiva de mulheres de classes populares (Alvarez, 1990:390; Drogus, 1999:41). No entanto, o sentido dessa atividade social, a trama de significados $e$ as condições que permitem a continuidade desse engajamento altruísta de mulheres continuam não compreendidos. Por que mulheres se engajam $e$ participam em comunidades e pastorais, dedicando seu tempo $e$ energia? Procuro responder essa questão ao tomar como objeto de análise as motivações e interesses presentes no engajamento $e$ militância nessas formas associativas.

As proposições de Gaxie (2005) quanto às retribuições à atividade militante são um recurso heurístico para a compreensão desse tipo de ação. $\mathrm{O}$ autor propõe que a militância, enquanto ação economicamente desinteressada, seja compreendida ao se considerar que ela aporta retribuições não materiais ou simbólicas, dadas pela concordância entre as respectivas ideologias, formas de ação e as disposições individuais dos engajados (Gaxie, 2005:179). Tais retribuições dizem respeito ao

\footnotetext{
${ }^{3}$ A participação feminina nas Comunidades Eclesiais de Base, enquanto problema de análise, mostra um distanciamento em relação à literatura que enfatizava o papel das $\mathrm{CEBs}$ no processo de democratização, ou de conscientização e participação política das classes populares. Para uma crítica dessa perspectiva, ver Couto, 2002:361.
} 
reconhecimento, prestígio, sentimento de importância, satisfação de agir no mundo para transformá-lo, poder sobre coisas e sobre pessoas (...) estima, afeto, admiração dos companheiros de luta, [ou ainda] sensações de apaziguamento, serenidade ou plenitude, satisfações morais, e até um sentimento de superioridade ética (Gaxie, 2005:162).

No caso das "líderes" em clubes de mães, comunidades e pastorais, essas recompensas existem a partir da adesão às formas de ação e a um conjunto de significados que dizem respeito à ação militante feminina. Se as "líderes" estão dispostas a investir ou "dar importância a um jogo social" (Bourdieu, 1996:139) - nesse trabalho e buscar suas recompensas é porque estes estão em afinidade com suas trajetórias sociais. Para compreender esse investimento, considero: 1) as recompensas ao trabalho militante, 2) as condições de exercício da liderança e 3) os significados e disposições presentes na atividade militante.

A pesquisa na qual se baseia esta análise foi realizada, entre 2002 e 2003, com "líderes" de comunidades de base católicas e também das Pastorais da Criança e da Mulher Pobre em periferias urbanas no Rio Grande do Sul. ${ }^{4}$ A pesquisa concentrou-se em dois bairros de periferia de um município contíguo a Porto Alegre, onde, no início da década de oitenta, mulheres mobilizadas por agentes religiosos, vinculados à tendência "progressista" da Igreja Católica, engajaram-se nos "clubes de mães" e "comunidades" católicas, e contribuíram para a organização e conformação física destes dois bairros, a partir de invasões de propriedade privada

4 O material obtido na pesquisa de campo constitui-se em doze entrevistas, realizadas por mim, com "líderes" e "agentes externos" que atuam hoje em dia ou atuavam nas $\mathrm{CEBs}$ na década de oitenta, folhetos diversos, números de um "jornal" produzido de forma artesanal - Mães Unidas - Voz da Libertação - por uma "agente externa" a partir de textos elaborados por mulheres participantes de clubes de mães na década de oitenta (aos quais também tive acesso), manuais, livros, jornais e documentos diversos da Pastoral da Criança, que são usados atualmente no trabalho comunitário, além do próprio diário de campo. 
Liderança de mulheres em pastorais e comunidades católicas

não ocupadas (Mammarella, 1996). Atualmente, existe nesses bairros a assim chamada "rede de comunidades" - organização do espaço geográfico, tendo como referência a Igreja Católica, fruto daquela atuação anterior.

\section{As recompensas da militância}

É possível demarcar dois momentos distintos da mobilização coletiva de mulheres de classes populares pela Igreja Católica: um de "formação" das comunidades em pauta, entre o final da década de setenta e o início da década de oitenta, no qual os marcos organizacionais do engajamento feminino são as comunidades eclesiais de base e clubes de mães, e o mais atual, no qual as referências da atuação de mulheres são, além das comunidades, a Pastoral da Criança e a Pastoral da Mulher Pobre. Embora nos antigos clubes as mulheres "fizessem a mesma coisa que agora", a denominação de "pastorais" para o trabalho voluntário feminino nas comunidades, em detrimento dos clubes de mães, está relacionada ao estado das relações de força entre os grupos da Igreja Católica, no qual a Teologia da Libertação perde legitimidade e os integrantes da ala "progressista" se engajam em formas de ação mais institucionalizadas (Della Cava, 2001). Os clubes de mães correspondem a um momento de mobilização dos leigos por agentes religiosos para causas definidas como "populares" (Della Cava, 1988; 1978; Drogus, 1997). As atuais pastorais estão mais ligadas à Igreja $e$ a seus trabalhos paroquiais, cotidianos e rotinizados e remetem a uma outra configuração das relações entre partidos, Estado, movimentos sociais e Igreja correspondente à "democratização". Embora esse processo tenha implicado em defecções e distanciamentos da participação nas comunidades, boa parte das mulheres que tomaram parte nos clubes de mães e em suas "lutas", atualmente, trabalha na Pastoral da Mulher Pobre ou na Pastoral da Criança - ambas as pastorais são formas de atuação possíveis para mulheres leigas 
engajadas como "líderes" nas comunidades religiosas em bairros de classes populares.

Nesse universo social, "Líder" é a qualificação usada para designar as mulheres de classes populares que desempenham continuamente atividades nessas formas associativas. Essa qualificação expressa uma diferenciação entre os membros da própria "comunidade" e implica na existência de uma hierarquia entre os fiéis, baseada em certas capacidades da "líder". A diferença entre as "líderes" e outras mulheres que participam das pastorais pode ser descrita como a possibilidade de reconhecimento da capacidade de planejamento e organização, ligados a alguma instrução. Por exemplo, uma mulher engajada na Pastoral da Criança que participou do processo de ocupação ocorrido no bairro, sendo sua mãe uma das antigas "líderes" do Clube de Mães, poderia ser uma "líder", como herdeira do trabalho materno nas "lutas" locais. No entanto, a "comunidade" a qual pertence não aceita sua liderança $e$ nem os trabalhos por ela propostos: costuras, tapetes, acolchoados feitos com restos de tecido, desqualificados como "lixo" que "junta muita sujeira, muito rato". A "líder" da Pastoral da Criança na comunidade, por sua vez, não participou da ocupação, tendo comprado o terreno onde possui sua casa, e é bem aceita pela comunidade. A outra, que se definiu como uma pessoa que "não sabe ler nem escrever, mal sabe rabiscar o nome", não pode, segundo a "líder", coordenar reuniões do Clube de Mães, pois

as mulheres vão lá e não querem ficar. (...) E, coitadinha, ela tem vontade de trabalhar, só que ela não sabe muita coisa. Então o pessoal não se anima. E eu não. Eu chego lá, [e] digo: "vamos fazer isso, vamos aquilo."

(N., coordenadora da Pastoral da Criança, 08/12/2002). ${ }^{5}$

5 As entrevistadas são indicadas com a abreviação de seus nomes, seguida da data em que foi realizada a entrevista. 
Liderança de mulheres em pastorais e comunidades católicas

Ao mesmo tempo, essa diferenciação corresponde a interesses diferenciados na participação em comunidades $e$ pastorais. Para algumas mulheres com menos recursos, as "bem pobrezinhas", as comunidades e pastorais permitem a inclusão em esferas de sociabilidade, aliada a certa possibilidade de satisfação de necessidades materiais, como a freqüencia a cursos de artesanato ou o recebimento de donativos como objeto da caridade e serviços da Igreja. Para outras, a constituição em "líder" aporta recompensas específicas. ${ }^{6}$

Entre as "líderes", a atividade militante está ligada à busca de satisfações morais e do reconhecimento das populações pelas quais elas atuam. Em primeiro lugar, é preciso notar que as "líderes" demarcam o espaço comunitário como incompatível com qualquer ganho material:

a gente vai vendo que ganhar o quê? Será que se trabalhar fora e ter salário eu ia ganhar alguma coisa? E não fazer nada pelo próximo? Acho que a vantagem que a gente tem aqui é que essas crianças precisam. (E.V., ex-"líder" da Pastoral da Criança, atualmente, "coordenadora" de uma creche comunitária, 03/06/2003).

Isso não significa que as "líderes" não obtenham ganhos de diferentes ordens com a militância. Uma delas, coordenadora da Pastoral da Criança, considera que com seu trabalho estava buscando também benefícios para sua família:

no momento que tu estás recebendo informação, tu vais aprendendo a ser uma melhor mãe, a buscar alternativas tanto de alimentação, quando da prevenção de doenças. (...). Então tudo isso vai modificando dentro da tua família. (...) Além de que a gente aprende a educar os filhos da gente da maneira correta, sabendo impor limites, a ter

6 Sobre as expectativas e gratificações associadas a hierarquias e diferenças nas organizações militantes, ver Gaxie (2005:182). 
diálogo com os filhos. Isso são bens que tu vais adquirindo (E., coordenadora da Pastoral da Criança, 06/06/2003).

Outra "líder" considera:

venci na minha vida (...) através dos trabalhos de pastoral, de comunidade e de CEBs... Foi através destes trabalhos que eu conheci o Rio de Janeiro, São Paulo, Belo Horizonte, e eu voei de avião (S., Pastoral da Criança e da Mulher Pobre, Alfonsín, 2001:37).

Essas recompensas de caráter "cultural", como o acesso a informações e universos sociais diferenciados, são indissociáveis dos ganhos do "coração", que se opõem diretamente aos ganhos materiais, como salienta a religiosa que assessora a Pastoral da Criança em um dos bairros:

Porque as mães saem lá de cima, da parada cinco, e vão lá embaixo, na [parada] vinte e três, ajudar a pesar. Elas pagam do dinheiro delas a passagem, ficam o dia todo trabalhando. Voltam feliz da vida de terem ajudado. Dinheiro, não ganham nada. O que elas ganham, vai no coração delas. É só a alegria de ajudar (12/06/2003).

Essa satisfação pessoal em "ajudar" aos necessitados vem junto com a "gratificação" de "ser reconhecida por isso":

se a gente está ajudando o próximo a gente se sente feliz com aquilo. Quando a gente passa na rua [é identificada com]: "Olha ali, a titia da sopa". A gente se sente feliz com as crianças chamarem a gente (...) e cumprimentam a gente... (I.V., Pastoral da Criança, 21.05.2003).

Essas recompensas podem ser compreendidas a partir do exame do conjunto das práticas de mediação de recursos nas quais elas se inscrevem, e que constituem o trabalho das "líderes". 
Liderança de mulheres em pastorais e comunidades católicas

\section{O exercício da liderança comunitária}

Como em outros casos de ações coletivas de grupos social ou politicamente dominados, a ação dos agentes religiosos constitui as causas, as estruturas organizacionais e os modelos de militância das mulheres de classes populares em pauta. ${ }^{7} \mathrm{O}$ "modo de organização e ação" (Gaxie, 2005:179) proposto pelos agentes religiosos pode ser descrito como mediação de ideologias, de técnicas, de repertórios de ação e de ampliação de redes de relações. Os agentes religiosos fornecem às "líderes" o acesso e o conhecimento de diferentes instituições - Igreja, partidos políticos, burocracias estatais. Esse acesso aporta saberes e recursos específicos à ação coletiva, como fontes de financiamento para suas ações; permite também a constituição de certo capital social, com o engajamento nas comunidades de advogados, engenheiros, jornalistas, sociólogos, "educadores" e, no caso da Pastoral da Criança, médicos, psicólogos e nutricionistas. É pelo exercício das mediações entre essas esferas $e$ as comunidades que algumas mulheres obtêm o reconhecimento como "líderes comunitárias".

Se a atuação das "líderes" é similar à mediação exercida pelos agentes religiosos, as lógicas a partir das quais atuam são distintas. Os agentes religiosos são partícipes de outras esferas

\footnotetext{
${ }^{7}$ No caso aqui tratado, os agentes religiosos atuaram junto às mulheres de classes populares em concorrência com partidos políticos pela definição do sentido da ação coletiva de grupos de classes populares (sobre essa concorrência, ver Mammarella, 1996). Sobre o papel dos agentes externos na definição do sentido da ação coletiva, ver Lagroye (1996:306); no caso específico dos religiosos que aderiram à Teologia da Libertação, ver Adriance (1991). Não é possível aqui fazer uma exposição mais detalhada de como a mobilização das classes populares por agentes religiosos católicos conecta-se com posições no espaço teológico, identificadas com as "teologias da libertação". No caso em pauta, para os agentes religiosos, trata-se da experiência de uma "catequese latino-americana", que se opõe a uma "catequese européia", e, especialmente para as mulheres "assessoras" de classe média, leigas ou religiosas, a atuação nas CEBs permite o investimento na elaboração erudita de "teologias sobre/da mulher" com base na experiência de assessoria. Para um maior detalhamento, ver Anjos (2005:206-15).
} 
sociais - como o espaço de elaboração teológica, o espaço escolar, instituições estatais, os espaços de definição legítima de exercícios profissionais -, nos quais sua experiência como "assessores de comunidades" e em "movimentos populares" pode funcionar como um capital $e$ proporcionar recompensas específicas, fruto do que Gaxie (2005:163) chama de multiposicionamento. Para as mulheres, o exercício de mediação de recursos e saberes para a população local circunscrita na "comunidade" resulta na sua constituição em uma referência em nível local.

A partir do engajamento nas comunidades e pastorais, as mulheres passam a adquirir os recursos que possibilitam o investimento em uma "carreira militante". É a "caminhada de comunidade" necessária a toda "líder". A partir do estímulo inicial ao trabalho comunitário dado pelos agentes religiosos, como o convite para participar das atividades da igreja (cursos de catequese dos filhos, fornos comunitários, grupos de reflexão, etc.), as mulheres "vão se descobrindo aos poucos" como capazes de liderar, e vão tomando para si ou recebendo outras atribuições no trabalho da Igreja. Este é um dos sentidos da "caminhada na comunidade", a experiência adquirida na prática. O engajamento inicial também é o período no qual algumas mulheres experimentam o contraponto da exclusão de outras esferas (como o mercado de trabalho e a escola), recebendo convites para coordenar grupos e fazer cursos. As mulheres sentem-se, então, "mais gente", em um meio onde não são desvalorizadas por sua condição social. Assim, sua atividade comunitária pode se estender para várias pastorais, como a da Criança, da Mulher, Operária, ou outros "movimentos" e mesmo a partidos políticos.

O trabalho comunitário não é possível sem a "formação", a "capacitação de lideranças", que "vêm de mãos vazias" para o trabalho comunitário, em cursos e palestras como formação da Pastoral da Criança, "teologia popular", "de Bíblia", "doutrina social da Igreja", "Direito do Trabalho pela Pastoral Operária", "Promotoras Legais Populares", "Violência contra a Mulher", 
Liderança de mulheres em pastorais e comunidades católicas

cursos de fitoterapia, de xaropes e pomadas, propiciados pela Igreja ou por setores próximos. Essa formação oferece às mulheres o "domínio dos esquemas de percepção e apreciação em obra na ideologia coletiva", possibilitando o falar em público, "na frente da comunidade", em momentos emblemáticos do reconhecimento de sua autoridade moral e religiosa.

A aparente "simplicidade" dos cursos sobre noções básicas de saúde, xaropes, pomadas, aleitamento materno, tem que ser recolocada em um contexto social de falta de recursos mínimos em matéria de saúde, saneamento e de informação. A disposição dos recursos comunitários e de informações básicas a serem disseminadas ou aplicadas "na prática" é capaz de garantir a sobrevivência dos atendidos pelas pastorais e tornar as "líderes" especiais, detentoras de algo raríssimo: noções que salvam vidas ou que ajudam a viver melhor. Essas mulheres sabem fazer xaropes e pomadas, soros e misturas alimentares, que tiram crianças da desnutrição e da morte, buscados em momentos críticos de doença por aqueles que não dispõem de outras formas de acesso à cura. Além disso, a disposição de saberes relativos ao tratamento de problemas de relacionamentos familiares, ou de violência doméstica, adquiridos junto à "voluntários, psicólogos, que dão palestra gratuitamente", é tão essencial na constituição da liderança que, mesmo entre as "líderes", há uma competição pelo monopólio desses saberes. Assim, segundo a religiosa que assessora a Pastoral da Criança em um dos bairros, entre as "líderes", há "muito ciúme uma da outra (...) competição entre elas", "se uma ["líder"] consegue uma palestrante para [sua] comunidade, não lembra de oferecer para as outras também" (I., $12 / 06 / 2003)$.

A mediação entre as populações locais "pobres" e outros grupos e instituições é outro fundamento da liderança comunitária. Em nome daqueles que têm necessidades, e de seus filhos, são as "líderes" que pedem doações e procuram recursos, reivindicam perante instituições públicas, pedem às empresas privadas, etc., tornando-se a "ponte" entre as instituições e o 
público a ser atingidos por programas de capacitação, incubadoras, economia popular solidária, que ganham certa ênfase em determinados programas governamentais.

Complementarmente, são elas que vão às casas ou distribuem as doações obtidas nas comunidades. Assim, as comunidades e pastorais configuram uma estrutura de mediação de benefícios na forma de "convênios", "parcerias" com poderes públicos ou entidades privadas para o atendimento às populações locais, com a implementação, por exemplo, de cursos profissionalizantes, ou de artesanato, alfabetização $e$ "reforço escolar". ${ }^{8}$ Como uma "líder" da Pastoral da Criança que está

cadastrada no Conselho Municipal dos Direitos da Criança e do Adolescente, então vem pra nós propostas de cursos, de espaços... É onde a gente tenta trazer para programas da comunidade. Então a gente pega esses [jovens] que estão mais correndo risco, e tenta resgatar eles de novo, [encaminhando-os para os cursos] (G., coordenadora da Pastoral da Criança, 28/04/2003).

Outra "líder" da Pastoral da Criança obteve do governo do Estado, a realização de cursos escolares para jovens e adultos de sua comunidade, além da realização de um "programa de reforço escolar" para jovens, que envolve uma entidade filantrópica e uma universidade local. Outras duas "líderes" mantêm uma creche com um projeto com verbas municipais, que proporcionava "reforço escolar" para crianças, e também administravam o repasse de cestas básicas vindas de um programa do governo do Estado para as famílias de sua rua. Uma delas é sempre procurada por assistentes sociais que querem fazer algum

\footnotetext{
8 Recentemente, as comunidades e pastorais contam com a possibilidade de obtenção de verbas de instituições diversas através de projetos, o que corresponde, inclusive, a uma diversificação do trabalho comunitário de mulheres, o qual não é feito somente nos marcos das estruturas comunitárias religiosas. Sobre as possíveis formas de sustentação da militância feminina em CEBs com o fim do processo de redemocratização, ver Drogus (1999).
} 
Liderança de mulheres em pastorais e comunidades católicas

trabalho no local, "e o pessoal daqui da vila acha que a gente tem que saber tudo. Já criou uma responsabilidade". Outra "líder", coordenadora da Pastoral da Mulher Pobre em um dos bairros, obteve uma verba estadual, durante três anos, para cursos de artesanato para mulheres com material reciclável.

O reconhecimento da liderança e de seu trabalho implica na disposição e administração dos recursos comunitários: são elas que decidem como serão utilizadas verbas e doações, que grupos e áreas serão beneficiados, como repartir os alimentos, quem será encaminhado aos cursos. Por exemplo, elas estabelecem critérios para as atendidas pelos trabalhos caritativos receberem doações. Como afirma uma coordenadora da Pastoral da Mulher Pobre, que estabeleceu o seguinte critério:

Todo mundo se ajuda [na comunidade]. Mas a pessoa tem que aprender a fazer alguma coisa. (...) As que são bem pobrezinhas, a gente arrecada. Todo fim de mês elas levam. Mas elas estão ali, ajudando a fazer um acolchoado, ajudando a fazer um chá, aprendendo a fazer um croché, ajudando a fazer uma pintura (N.J., 05/12/2002).

Esta disposição dos recursos comunitários permite que, por exemplo, uma "líder" comunitária ligada à Pastoral da Criança repreenda uma mulher que não estava mais trazendo seus filhos às tardes de pesagem e, além disto, fora vista pedindo alimento em outras comunidades. No período da pesquisa de campo, surgiram atritos entre as "lideranças" das pastorais de um dos bairros, porque as doações arrecadadas nas várias comunidades estavam sendo centralizadas em uma única comunidade e uma "líder" "estava fazendo a partilha sozinha", o que dificultava às outras "líderes" fazerem doações em suas comunidades.

O controle dos recursos, que é parte do trabalho de mediação, constitui estas mulheres, aos olhos de seu público, como aquelas que, de alguma forma, são responsáveis pela resolução de seus problemas. Isso aparece na descrição das 
"visitas" às casas dos atendidos, um momento em que elas também fazem doações de alimentos e roupas:

Com a visita, ... Meu Deus do céu, parece que chegou Deus na casa deles. E quando a gente (...) consegue levar um alimento, (...) como elas ficam felizes. Faltam só se ajoelhar e beijar os pés da gente. Elas pensam que é a gente. Eu digo: "Eu consigo, mas não sou eu que estou dando. Eu consigo através de outras pessoas" (I., "líder" da Pastoral da Criança, 21/05/2003).

Esse investimento na mediação e em um trabalho que implica na doação de si confere o reconhecimento da comunidade. Por outro lado, a procura desse reconhecimento, por parte das "líderes", está relacionada à adesão a um conjunto de noções que dão sentido à atividade militante e à sua própria condição feminina.

\section{Os significados da atividade militante}

A militância em pastorais e comunidades é expressa ${ }^{9}$ em um vocabulário polissêmico. Nesse vocabulário, o trabalho comunitário é apresentado como "ajuda" aos "necessitados" (seja como expressão da caridade da "líder", seja como demanda às autoridades públicas), dada com "alegria no coração, porque elas sabem que mais tarde esses serviços que nós fizemos todas juntas vão servir a nós mesmas" ("Seguidoras de Cristo - Divino Mestre", documento manuscrito). Mas ele pode remeter também à política, quando o trabalho é apresentado como "luta" por "direitos". As

\footnotetext{
9 Utilizo também para análise os documentos escritos por integrantes de clubes e comunidades na década de oitenta, os quais, tanto quanto as entrevistas com as "líderes", constituem uma fonte privilegiada das categorias e noções partilhadas pelos integrantes das comunidades, além de apresentar uma primeira sistematização das idéias-força presentes na prática coletiva e no vocabulário das atuais "líderes".
} 
Liderança de mulheres em pastorais e comunidades católicas

"lutas" referem-se a eventos, como a formação de "uma comissão de mães" que

foi à secretaria da saúde falar com o secretário sobre a ampliação do posto médico há seis meses atrás. Ele nos prometeu a ampliação dentro de três meses e agora fomos outra vez e ele nos prometeu e cumpriu a palavra. $O$ posto médico já está em construção. Graças à comissão que a nossa caminhada foi vitoriosa ("Clube de mães Jesus Operário está feliz" - documento manuscrito).

Ou, ainda, à atuação das "mães das vilas". que "vêm reivindicando uma escola de primeiro grau completo, no fundo das vilas" junto à Secretária de Ensino (Mães Unidas - Voz da Libertação, ago. 1987:8).

Esse vocabulário é polissêmico também porque as mulheres mobilizadas se apropriam das categorias presentes no discurso dos agentes religiosos e as re-significam, utilizando-as para expressar a condição de "pobre" e seus "problemas". Este é o caso da categoria "luta". Como se observa em escritos de mulheres participantes de clubes de mães na década de oitenta: "vida de pobre é difícil, se resume em lutas" ("Vida de pobre" - documento manuscrito); ou "peço a Deus que ajude a todas as mães daí de [município], que elas não desanimem na luta [com] que estão enfrentando os problemas" ("Clube de Mães Nossa Senhora Aparecida" - documento manuscrito). Por sua vez, a categoria "ajuda" também pode ser usada para expressar a assimetria social nas demandas aos ocupantes de cargos públicos, entendida como "luta por direitos": uma integrante do clube de mães se dirige ao prefeito em nome da

necessidade, pela sobrevivência e o bem-estar de nosso povo, pedindo proteção [considerando-o eleito] pelo povo, [como] nosso protetor, [e por isso] não precisamos pedir isto ou aquilo porque confiamos $e$ acreditamos que $o$ 
senhor vai nos ajudar ("Pelo direito de viver" - documento manuscrito).

"Direitos", "ajuda" e "lutas" são categorias que permitem conciliar demandas a órgãos públicos e assistência social a partir de princípios cristãos, atendendo necessidades concretas de populações com poucos recursos econômicos, culturais ou sociais.

Tanto a "ajuda" quanto os "direitos" e as "lutas" fazem parte do referencial comunitário, no qual a identificação com uma população local, suas condições de existência, "questões" ou "problemas" fundamenta a mobilização. A existência de escola, saúde, calçamento, etc. é entendida como aquilo que torna possível a vida comunitária, e sua obtenção é possível pela ação da "comunidade" representada pelas "líderes". Assim, esse referencial enfatiza a "união de todos", o "mutirão", a "fraternidade comunitária" e o "compromisso de todos com o bem comum". Essa concepção seria própria à experiência de vida $e$ às origens sociais dos agentes religiosos - as populações descendentes da imigração européia e de origem rural difundidas entre os "pobres" de periferias urbanas (Della Cava, 1978:250-251). É este referencial, segundo o qual a "comunidade" deve ser a inspiradora de todas as "lutas" $e$ formas de mobilização, que permite conciliar os diferentes significados da ação militante. Isso porque esse referencial comunitário oferece uma visão de mundo coerente e estruturada (Banck, 1990:75), que dá base ao entretenimento de uma identidade de grupo, como "pobres", amparados por Deus nas "lutas" por seus "direitos". ${ }^{10}$ Obtidos pelas "lutas", os direitos são fundamentados por uma "LEI JUSTA, lei NATURAL (...). Quando a sociedade $e$ as autoridades se OMITEM, o POVO SE ORGANIZA E VAI EM BUSCA DE SEUS DIREITOS. (...)" (Mães Unidas - Voz da Libertação, maio de 1987:9, caixa alta no original). Nesse sentido, as "causas" dos

${ }^{10}$ Nesse sentido, é possível falar na constituição de uma identidade a partir da explicitação de problemas, antes, "em estado de experiência individual ou serial, mal-estar, ansiedade, expectativa, inquietação" (Bourdieu, 1998:142). 
Liderança de mulheres em pastorais e comunidades católicas

"pobres" são legitimadas por uma instância supra-social, ao mesmo tempo em que há um investimento intenso em uma identidade que permite fazer frente à "inimigos fortes ou períodos difíceis" (Pizzorno, 1988:385), comum a diferentes movimentos sociais dedicados às "lutas dos pobres".

A atividade militante também se dá pela adesão a uma ideologia relativa à participação feminina no espaço público, que atribui explicitamente um papel à mulher nas "lutas" dos "pobres". O "cuidado das crianças" e da "comunidade" materializados nas "lutas" por creches, escolas, postos de saúde, saneamento, luz elétrica podem ser entendidos como uma forma de enquadramento da atividade feminina na, e a partir da, Igreja, impondo uma concepção de condição feminina: a mulher como ligada ao cuidado, à criação e à maternidade ${ }^{11}$, atualizando o "marianismo" (Drogus, 1997:60-1). Nesse sentido, essa definição se constitui em uma contraposição simbólica e prática a outras modalidades de engajamento feminino, em especial o feminismo. ${ }^{12}$ No entanto, além de reproduzir ideologias tradicionais sobre condição feminina (Alvarez, 1990:390; Drogus, 1999:41), ou de se constituir em um sentido imputado à ação de mulheres de classes populares (Bonetti, 2007:2), tal concepção implica em uma promoção simbólica da "mulher pobre" a ser resignificada pelas mulheres as quais é oferecida e se constituir em fundamento de ganhos morais.

Nessa concepção, a mulher é a principal agente nas lutas sociais porque é responsável pela vida - ela gera, dá a luz, "dá seu sangue e seu leite" ao filho, à nova vida. Isso faz com que ela seja "responsável" pela vida no mundo. A ênfase popular nessa variação do temário católico sobre os "poderes femininos" radicados na condição de mãe comporta a re-significação das

${ }^{11}$ Sobre a imposição da maternidade como condição feminina legítima, ver Anjos, 2007.

${ }^{12}$ Sobre as tomadas de posição anti-feministas da Igreja Progressista, ver Alvarez, 1990:389-90. 
"mulheres da Bíblia", em um trabalho de analogia e identificação com as "mulheres pobres" mobilizadas como as "mães do povo", e como as mais pobres dentre os pobres, aquelas que "sofrem a opressão mais profunda" (Pastoral da Mulher Pobre, 1988:77):

O que é ser Maria hoje? Muitas mães pobres estão seguindo o exemplo de Nossa Senhora. Elas procuram ser como Maria quando se colocam em disponibilidade, saindo de casa para ajudar outras mães, trabalhando nos clubes e em todos os serviços da comunidade, lutando por moradia, educação, saúde, empregos e melhores salários (Mães Unidas - Voz da Libertação, maio de 1987:1).

A constituição das causas femininas ligadas à precariedade das condições de existência do povo, do "pobre", vem acompanhada da valorização tanto da "força da mulher", de sua "energia", quanto da união de esforços com os homens pobres, na "luta" conjunta, "luta" que a mulher "puxa", por melhores condições de vida. Em vários momentos as "líderes" enfatizam que sua definição de "lutas das mulheres" envolve "a mulher que se organiza e ao homem dá a mão", inclusive como contrária ao "feminismo", no qual as mulheres seriam "contra os homens". Uma "líder" de comunidade engajada na Pastoral da Criança, e que, freqüentou grupos de mulheres na década de oitenta, afirmou: "não éramos feministas. A feminista, o pouco que a gente sabia, elas eram contra os homens na sociedade. Nós não, a gente precisava deles" (D., 25/05/2003). Outra, que na década de oitenta participou dos clubes de mães e das invasões no bairro $e$ atualmente coordena a Pastoral da Mulher Pobre em uma paróquia, considera que "a mulher não pode caminhar sozinha, excluindo o homem. Para isso ela é mãe, ela é mãe da mulher e mãe do homem" (A., 30/06/2003). Nessa complementaridade de esforços na luta comum, a mulher tem que ser valorizada por seus atributos e aí ocorre a inversão do sinal negativo da condição de mãe e mulher pobre, numa espécie de "poor housewife is beautiful". Isso está presente em toda a prática celebratória - 
Liderança de mulheres em pastorais e comunidades católicas

reuniões, festas, encontros - e na apresentação iconográfica dessas pastorais, cujas fotos e desenhos de mulheres, mães, "pobres", e seus filhos, em torno de suas casas, apresentam uma estética que foge aos padrões dominantes de beleza feminina.

Essas "lutas" e a adesão à imagem de mulher presente nelas justificam que donas-de-casa, que são as "líderes" de pastorais $e$ clubes de mães, deixem seus lares e "participem" nas boas causas que são as melhorias das condições de vida da comunidade e o cuidado de suas crianças. Essa ideologia da força da mulher pobre está de acordo com as gestões das carreiras militantes das "líderes". Em diferentes situações apareceram tensões, ou mesmo os conflitos, com os maridos, devido à participação nas pastorais, com casos extremos de separação, ou com o estabelecimento de certas "regras" para evitar conflitos, como não participar em nenhuma atividade à noite, pois "o [marido] gosta de chegar, eu estar em casa, com a janta pronta, claro, esperando por ele" (I.V., "líder" da Pastoral da Criança, 21/05/2003). Ao mesmo tempo, essas mulheres se vêem como "libertas" $e$ "conscientizadas" pela participação em clubes e pastorais. As mulheres como força motriz das lutas devem ser respeitadas por seus maridos e filhos. Esse é um dos sentidos da "libertação", a partir da militância adquirem autoridade moral, saberes e um certo capital social que seus maridos não possuem. Uma "líder" da Pastoral da Criança e da Pastoral da Mulher Pobre expôs sua própria "libertação" do "medo muito grande" e "das garras do marido", como efeito de sua participação "nos movimentos, reuniões" em que foi "abrindo os olhos" (S., 19/05/2003).

Assim, elas demonstram às outras mulheres os ganhos de participar nas pastorais: obtenção de informações relativas à condução da vida familiar e privada, na "formação, na experiência captada no grupo, onde se discute os problemas" entre mulheres que "eram muito desvalorizadas, sofriam, apanhavam dos homens". É nas comunidades que as mulheres ganham 
força para elas saírem daquele mundinho, [tornando-se] umas mulheres libertas. Elas não têm mais aquele vínculo que a mulher é só para dentro de casa, é só para o marido, é só para cozinhar, cuidar dos filhos e lavar roupa (S., "líder" da Pastoral da Criança e da Pastoral da Mulher Pobre, $19 / 05 / 2003)$.

Ao mesmo tempo, elas passam a questionar "aqueles costumes antigos, do tempo que eu fui criada", em que suas atitudes, porte, roupas eram rigidamente regrados: "eu não usava bermuda, não usava short, que eu era feia, que eu era velha, que eu era gorda". Essas mulheres passam, então, a se verem como exemplos de libertação a serem seguidos por outras, às quais passam a informar seus "direitos"

de trabalhar, de se arrumar, de ser alguém na vida. (...) E ela tem que fazer o marido respeitar ela como mulher. E aí eles não ficam tão machão, e aí elas também dão força para ele. Porque aí ele sente a força dela (S., "líder" da Pastoral da Criança e da Pastoral da Mulher Pobre, 19/05/2003).

A valorização da força feminina, se originada no catolicismo, permite às "líderes" expressarem seu papel nas comunidades: não permitir que seus atendidos desanimem, $e$ continuem a "lutar".

Por isso a gente tem que estar encaixada em todos os trabalhos onde necessita da presença da gente, mostrar para as outras mulheres essa força que nós temos, essa responsabilidade que Deus nos deixou, como geradoras de vida (E., coordenadora da Pastoral da Criança, 06/06/2003).

É possível identificar nas "líderes" entrevistadas certas disposições que as habilita ao trabalho de liderança $e$ a conceber este trabalho como realização pessoal. No caso, os trajetos escolares e profissionais dessas mulheres estão estreitamente 
Liderança de mulheres em pastorais e comunidades católicas

relacionados com a identificação com o papel de dona-de-casa e mãe "pobre", necessário à continuidade do engajamento em clubes e pastorais. Seus parcos recursos sociais de origem as afasta da escola, as leva a uma inserção precoce no mercado de trabalho e a um investimento na esfera doméstica como dona-de-casa $e$ mãe. Esse investimento, às vezes, é secundado por atividades informais - trabalho em tempo parcial, a domicilio, etc. - como parte de estratégias familiares de manutenção. $\mathrm{O}$ investimento no trabalho voluntário nas comunidades, pastorais e "lutas" nas quais a Igreja Católica está presente, fundado na doação e no desinteresse material, é, assim, correlato à exclusão ou inserção precária no mercado de trabalho dessas donas-de-casa (Schmink, 1981).

A promoção simbólica presente na formulação de uma ideologia relativa à "mulher pobre" oferece às mulheres engajadas nessas formas associativas a possibilidade de definir e expressar o investimento de si enquanto dona-de-casa de classes populares no trabalho de liderança. Ao mesmo tempo, a ideologia referente à condição feminina presente em pastorais e comunidades é também apropriada, porque dá expressão à autoridade moral das "líderes". Ela oferece uma identidade adequada aos recursos que dispõem, às suas origens sociais $e$ ao espaço de militância "popular" no qual estão engajadas como "líderes".

\section{Considerações finais}

Esta análise procurou dar conta das motivações e interesses presentes na militância de mulheres de classes populares em espaços associativos ligados à Igreja, em nome de causas que remetem ao altruísmo e ao dom de si. A diferenciação entre "líderes" e demais participantes das comunidades é correlata à possibilidade de existência de variadas recompensas ao engajamento. Assim, para as "líderes", é possível identificar recompensas "práticas", como a aquisição de saberes a serem revertidos na própria vida familiar, e a mudança de relações de 
poder nesta esfera. Ou, ainda, uma certa ampliação de seu capital social, com o estabelecimento de redes de relações para além do espaço comunitário. No entanto, tais recompensas são parte de uma atividade voltada à aquisição e manutenção de um capital simbólico, o reconhecimento dos atendidos. Esse reconhecimento é um dos objetivos do trabalho de mediação e implica no estabelecimento de laços sociais pela doação de energia, tempo $e$ objetos.

Além disso, muito mais do que implicar na afirmação de ideologias católicas relativas à condição feminina, o exercício da militância é parte da apropriação de uma identidade positiva $e$ "digna" como "mulher pobre". Essa é parte das recompensas simbólicas à atividade militante. Essa identidade, para as "líderes", reverte o estigma do pertencimento às classes populares, expressa sua superioridade moral perante a família e a comunidade e se constitui mesmo em um revide à sua exclusão de outras esferas sociais.

\section{Referências bibliográficas}

ADRIANCE, Madeleine. Agents of change: the roles of priests, sisters and lay workers in the grassroots catholic church in Brasil. Journal for the Scientific Study of Religion, vol. 30, n 3, Oxford, 1991, pp.292-305.

Alfonsín, Ana Isabel de Moraes. Empoderamento das mulheres de base em movimentos e pastorais sociais no município de Porto Alegre e região metropolitana. Monografia em Ciências Sociais, PUC-RS, 2001.

AlVAREZ, Sônia. Women's participation in the Brazilian "peoples church": a critical appraisal. Feminist Studies, vol. 16, n 2, Maryland, summer 1990, pp.381-408.

ANJOS, Gabriele dos. "Mulheres todas santas": participação de mulheres em organizações religiosas e definições de condição feminina em igrejas cristãs no Rio Grande do Sul. Tese de doutorado em Sociologia, Universidade Federal do Rio Grande do Sul, 2005. 
Liderança de mulheres em pastorais e comunidades católicas

Maternidade, cuidados do corpo e civilização na Pastoral da Criança. Revista Estudos Feministas, vol. 15, nº 1, Florianópolis, abril 2007, pp.27-44. (http://www.scielo.br/pdf/ref/v15n1/a03v15n1.pdf).

BANCK, Geert A. Cultural Dilemmas behind Strategy: Brazilian Neighbourhood Movements and Catholic Discourse. The European Journal of Development Research, vol. 2, n. 1, june 1990, pp. 65-88.

BONETTI, Alinne de Lima. Para além da "maternidade militante": ativismo de mulheres de base no campo político feminista contemporâneo. Anais da Reunião de Antropologia do Mercosul, 7, Porto Alegre, 2007, CD-ROM.

BOURDIEU, Pierre. É possível um ato desinteressado? In: Razões práticas: sobre a teoria da ação. Campinas, Papirus, 1996, pp.137-156.

Espaço social e gênese das "classes". In: O poder simbólico. Rio de Janeiro, Bertrand Brasil, 1998, pp.133-161.

BURDICK, John. Gossip and Secrecy: Women's Articulation of Domestic Conflict in Three Religions of Urban Brazil. Sociological Analysis, vol. 50, n 2, 1990, pp.153-170.

CouTO, Márcia Thereza. Na trilha do gênero: pentecostalismo e CEBs. Revista Estudos Feministas, vol. 10, $\mathrm{n}^{\circ}$ 2, Florianópolis, 2002, pp.357-369.

Della CAVA, Ralph. A Igreja e a abertura, 1974-1985. In: STEPAN, Alfred. (org.) Democratizando o Brasil. Rio de Janeiro, Paz e Terra, 1988, pp.231-273.

. Política a curto prazo e religião a longo prazo: uma visão da Igreja Católica no Brasil (em abril de 1978). In: RIBEIRO, Darcy et alli. Encontros com a Civilização Brasileira. Rio de Janeiro, Civilização Brasileira, 1978, pp.242-258.

Transnacional Religions: The Roman Catholic Church in Brazil and the Orthodox Church in Rússia. Sociology of Religion, Winter, 2001 (http://www.findarticles.com/p/articles/mi_m0SOR/is _ 4_62/ai_82477980 - acesso em 08/08/2003).

DroGus, Carol Ann. No Land of Milk and Honey: Women CEB Activists in Posttransition Brazil. Journal of Interamerican Studies and World Affairs, vol. 41, n 4 , winter 1999, pp.35-51.

Women, Religion and Social Change in Brazil's Popular Church. Notre Dame, Indiana, University of Notre Dame Press, 1997. 
GAXIE, Daniel. Économie des parties et rétributions du militantisme. Revue française de science politique, Paris, février 1977, pp.123-154.

Rétributions du militantisme et paradoxes de l'action collective. Swiss Political Science Review, vol. 11, $\mathrm{n}^{\circ}$ 1, St. Gallen, Suiça, 2005, pp.157-188.

Lagroye, Jacques. Sociologie Politique. Paris, Presses de la Fondation Nationale des Sciences Politiques et Dalloz, 1996.

LANDIM, Leilah e SCALON, Maria Celi. Doações e trabalho voluntário no Brasil: uma pesquisa. Rio de Janeiro, Sete Letras, 2000.

MACHADO, Maria das Dores C. e MARIZ, Cecília L. Mulheres e prática religiosa nas classes populares: uma comparação entre as igrejas pentecostais, as Comunidades Eclesiais de Base e os grupos carismáticos. Revista Brasileira de Ciências Sociais, vol. 12, no 34, São Paulo, 1997, pp.71-87.

MAMmARELLA, Rosetta. Práticas coletivas e autonomia num movimento popular urbano: o caso da Vila Santo Operário 1979-1990. Dissertação de Mestrado, Sociologia, Universidade Federal do Rio Grande do Sul, 1996.

PAStORAL da mulher pobre. Mulher Comunidade - A Nova Mulher. Petrópolis, Vozes, 1988.

Pizzorno, Alessandro. Algum tipo diferente de diferença: uma crítica das teorias da "escolha racional". In: FOXLEY, Alejandro; MCPHERSON, Michael; O'DONNELL, Guillermo. (orgs.) Desenvolvimento e política$e$ aspirações sociais. $O$ pensamento de Albert $O$. Hirschman. São Paulo, Vértice/Editora Revista dos Tribunais, 1988, pp.366-386.

SCHMINCK, Marianne. Women in Brazilian Abertura Politics. Signs: Journal of women in culture and Society, vol. 7, $\mathrm{n}^{\circ}$ 1, autumn 1981, pp.115-134.

\section{Outras fontes}

Clube de mães Jesus Operário está feliz... [Canoas]: s.e., [198-]. (manuscrito).

Clube de mães Nossa Senhora Aparecida (da Ilha Grande dos Marinheiros). [Porto Alegre]: s.e., [198-]. (manuscrito).

Mães Unidas - Voz da Libertação. Pastoral da Mulher Pobre, Porto Alegre, set.-out. de 1988. Datilografado. 
Liderança de mulheres em pastorais e comunidades católicas

Mães Unidas - Voz da Libertação. Pastoral da Mulher Pobre, Porto Alegre, maio de 1987. Datilografado.

Mães Unidas - Voz da Libertação. Pastoral da Mulher Pobre, Porto Alegre, setembro de 1987. Datilografado.

Pelo direito de viver. [Canoas]: s.e., [198-]. (manuscrito).

Seguidoras de Cristo - Divino Mestre. [Canoas]: s.e., [198-]. (manuscrito).

Vida de pobre. [Canoas]: s.e., 1987. (manuscrito). 